\title{
Evaluation of Quantitative Characteristics in Some Mutant Lines of Nigella sativa L.
}

\author{
Animesh K. Datta and Amal K. Biswas \\ Department of Botany, University of Kalyani, Kalyani 741235, India
}

Accepted December 12, 1984

Induction of mutation forms an important part of breeding programme which aims at the improvement of crop plants through manipulation of genetic variation (Gaul 1964, Micke 1969, Sigurbjörnsson 1976, Brock 1977). By the mutation research work of the present authors for last several years, creation of genetic diversities was possible in Nigella sativa L. (black cummin), a spice yielding member of the family Ranunculaceae, and several mutant lines have been recovered (Datta and Biswas 1985). In this communication, the findings on the quantitative characteristics observed in the mutants have been presented.

\section{Material and methods}

Quantitative traits were studied in the $\mathrm{M}_{2}, \mathrm{M}_{3}$ and $\mathrm{M}_{4}$ generations of the mutant lines. Selfed seeds of individual $\mathbf{M}_{2}$ viable mutants (cited in tables) were sown for $\mathbf{M}_{3}$ and subsequent generations. The true breeding mutant plants were grown in randomized block design with three replications in the experimental plots during $\mathrm{M}_{3}$ and $\mathrm{M}_{4}$ generations. But in prostrate, brown seed-coat and dwarf mutant plants, three replications could not be performed due to paucity of selfed seeds. Selfed seeds of individual mutants were sown in lines keeping a uniform distance $15 \mathrm{~cm}$ between the plants and $25 \mathrm{~cm}$ in between the lines. In each plot, the mutants were alternatively sown in lines with control seeds and in all cases border effect was avoided by growing control plants along the boundary line of the plot.

Morphological variations were studied in the mutants as well as in the control. The variations were assessed from seed germination, seedling survivability, plant height, number of primary and total branches, number of capsules per plant, capsule length per fruit, number of compartments per capsule, seed-set per fruit (fitted seeds), 100-seed weight, seed size (length and thickness) and harvest index. Harvest index was calculated by using the formula:

Harvest index $(\mathrm{HI})=\frac{\text { Economic yield (seed yield/plant) }}{\text { Biological yield (total dry wt./plant) }} \times 100$.

Seed size was measured by using a diallel gauze. All sterility types (flower, capsule, pollen and seed) were represented in percentages.

In addition to these observations, the extent of variations among control plants of different years and between control and mutant lines growing under uniform environmental conditions were studied by means of analysis of variance. 


\section{Results and discussion}

\section{Germination and survival}

Since the mutants were identified in $\mathrm{M}_{2}$ generation frequency of germination and survival of the individual mutants could be recorded in the $\mathbf{M}_{3}$ and $\mathbf{M}_{4}$ generations (Table 1). As compared to the respective controls, the feathery leaf mutant has demonstrated increased frequency of germinability and survivality; while minimum percentage of germination and survival were noted in the prostrate mutant plants (Table 1). Percentage of germination and survival of the brown seed-coat mutant could not be recorded at $\mathrm{M}_{3}$ generation, because the mutant trait was not possible to identify before harvest; obviously artificial self pollination has not been made possible in the unidentified mutant. Consequently, seeds from only open pollinated mutant plants were recovered in the $\mathbf{M}_{2}$ generation. Slightly higher frequencies of germinability and survivality were recorded in most of the mutants at

Table 1. Germinability and survivality of seedlings of control and mutant plants

\begin{tabular}{|c|c|c|c|c|c|c|c|c|c|c|}
\hline \multirow{3}{*}{$\begin{array}{l}\text { Plant } \\
\text { types }\end{array}$} & \multicolumn{5}{|c|}{$\mathrm{M}_{3}$ generation } & \multicolumn{5}{|c|}{$\mathbf{M}_{4}$ generation } \\
\hline & \multirow{2}{*}{$\begin{array}{l}\text { No. of } \\
\text { seeds } \\
\text { sown }\end{array}$} & \multicolumn{2}{|c|}{ Germination } & \multicolumn{2}{|c|}{ Survival } & \multirow{2}{*}{$\begin{array}{l}\text { No. of } \\
\text { seeds } \\
\text { sown }\end{array}$} & \multicolumn{2}{|c|}{ Germination } & \multicolumn{2}{|c|}{ Survival } \\
\hline & & $\begin{array}{l}\text { Fre- } \\
\text { quency }\end{array}$ & $\%$ & $\begin{array}{l}\text { Fre- } \\
\text { quency }\end{array}$ & $\%$ & & $\begin{array}{l}\text { Fre- } \\
\text { quency }\end{array}$ & $\%$ & $\begin{array}{l}\text { Fre- } \\
\text { quency }\end{array}$ & $\%$ \\
\hline Control & 200 & 164 & 82.00 & 164 & 82.00 & 2620 & 1863 & 71.30 & 1868 & 71.30 \\
\hline Lax branching & 556 & 308 & 55.40 & 271 & 48.74 & 180 & 108 & 60.00 & 87 & 48.33 \\
\hline Feathery leaf & 129 & 119 & 92.25 & 108 & 83.72 & 120 & 100 & 83.33 & 94 & 78.33 \\
\hline Bushy & 80 & 36 & 45.00 & 31 & 38.75 & 120 & 68 & 56.67 & 68 & 56.67 \\
\hline Dwarf & 19 & 9 & 47.37 & 05 & 26.32 & 50 & 29 & 58.00 & 21 & 42.00 \\
\hline Viridis & 100 & 66 & 66.00 & 61 & 61.00 & 160 & 118 & 73.75 & 105 & 65.63 \\
\hline $\begin{array}{l}\text { Early } \\
\quad \text { flowering }\end{array}$ & 50 & 26 & 52.00 & 25 & 50.00 & 120 & 69 & 57.50 & 66 & 55.00 \\
\hline $\begin{array}{l}\text { Brown } \\
\quad \text { seed coat }\end{array}$ & - & - & - & - & - & 80 & 69 & 86.25 & 61 & 76.25 \\
\hline Prostrate & 15 & 5 & 33.33 & 02 & 13.00 & 25 & 06 & 24.00 & 04 & 16.00 \\
\hline
\end{tabular}

Table 2. Rate of germination of $\mathbf{M}_{3}$ seeds in control and mutant plants at field condition

\begin{tabular}{lccccccc}
\hline \multirow{2}{*}{ Plant types } & $\begin{array}{c}\text { No. of } \\
\text { seeds }\end{array}$ & \multicolumn{7}{c}{ Germination (\%) } \\
\cline { 3 - 8 } & sown & 15 days & 20 days & 25 days & 30 days & 35 days & 40 days \\
\hline Control & 2620 & 45.95 & 70.34 & 71.30 & 71.30 & 71.30 & 71.30 \\
Lax branching & 180 & 52.77 & 60.00 & 60.00 & 48.33 & 48.33 & 48.33 \\
Feathery leaf & 120 & 82.50 & 83.33 & 78.33 & 78.33 & 78.33 & 78.33 \\
Bushy & 120 & - & 4.17 & 9.17 & 42.50 & 56.67 & 56.67 \\
Dwarf & 50 & 22.00 & 28.00 & 48.00 & 58.00 & 42.00 & 42.00 \\
Viridis & 160 & 38.13 & 73.75 & 73.75 & 67.50 & 65.63 & 65.63 \\
Early flowering & 120 & 57.50 & 55.83 & 55.00 & 55.00 & 55.00 & 55.00 \\
Brown seed coat & 80 & 58.75 & 86.25 & 86.25 & 82.50 & 76.25 & 76.25 \\
Prostrate & 25 & - & - & 8.00 & 12.00 & 16.00 & 16.00 \\
\hline
\end{tabular}


$\mathbf{M}_{4}$ generation as compared to their respective control (Table 1).

The rate of germination was observed in the $\mathrm{M}_{4}$ generation after 15, 20, 25, 30, 35 and 40 days of sowing (Table 2, Fig. 1). Maximum germination in the control plants was recorded after 25 days of sowing, while in feathery leaf, lax branching, viridis, early flowering and brown seed coat mutants germination was found to be completed within 20 days of sowing but delayed rate of emergence was noted in bushy, dwarf and prostrate mutants (Table 2, Fig. 1). The first count of germinated seedlings in the field was made after 15 days of sowing but the prostrate and bushy mutants failed to germinate within this period, although the feathery leaf mutant has shown maximum frequency of germination within the said period (Table 2).

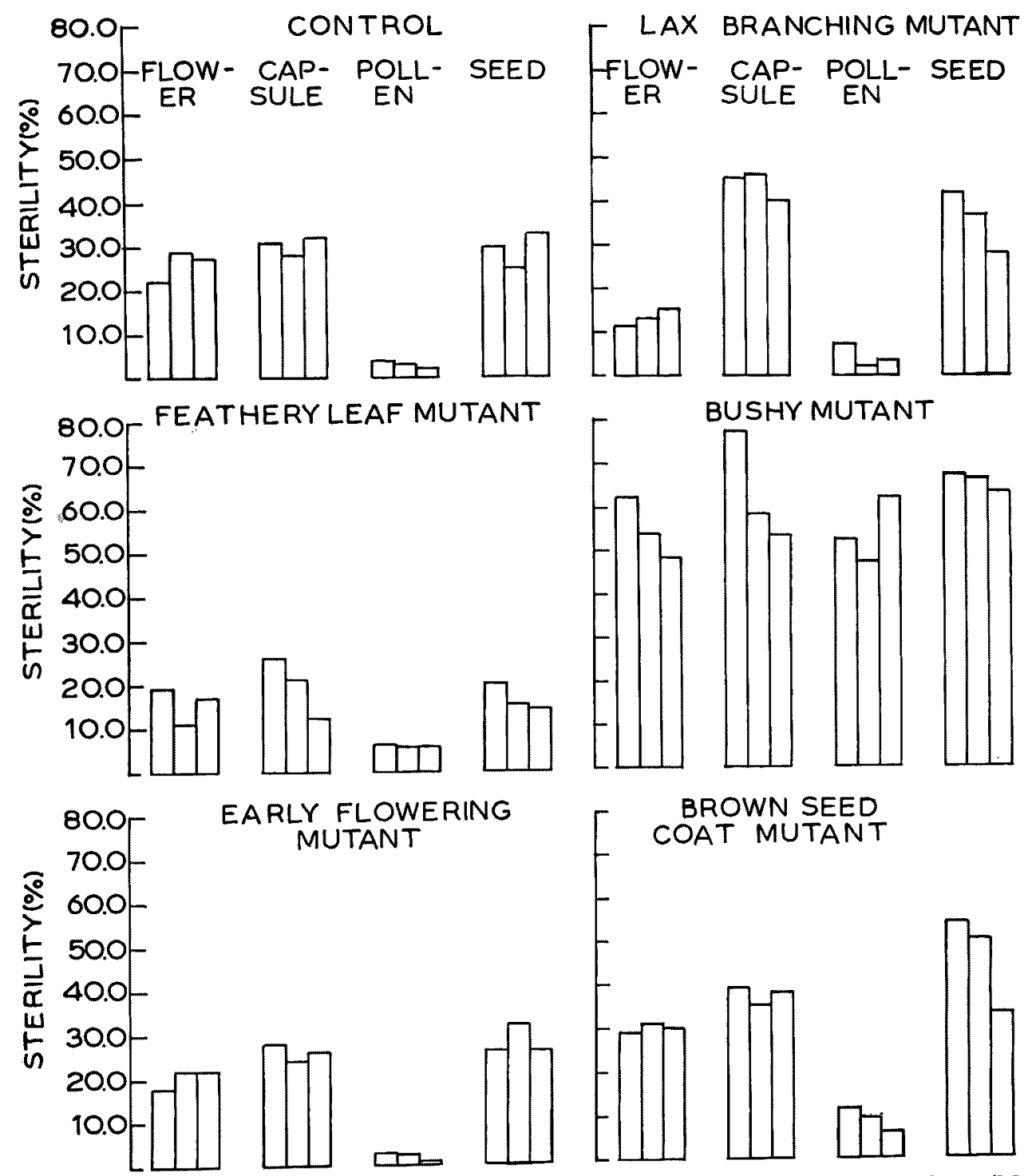

Fig. 1. Graph shows rate of seed germination in control and in different mutant plants $\left(\mathrm{M}_{4}\right.$ generation) of $N$. sativa. 


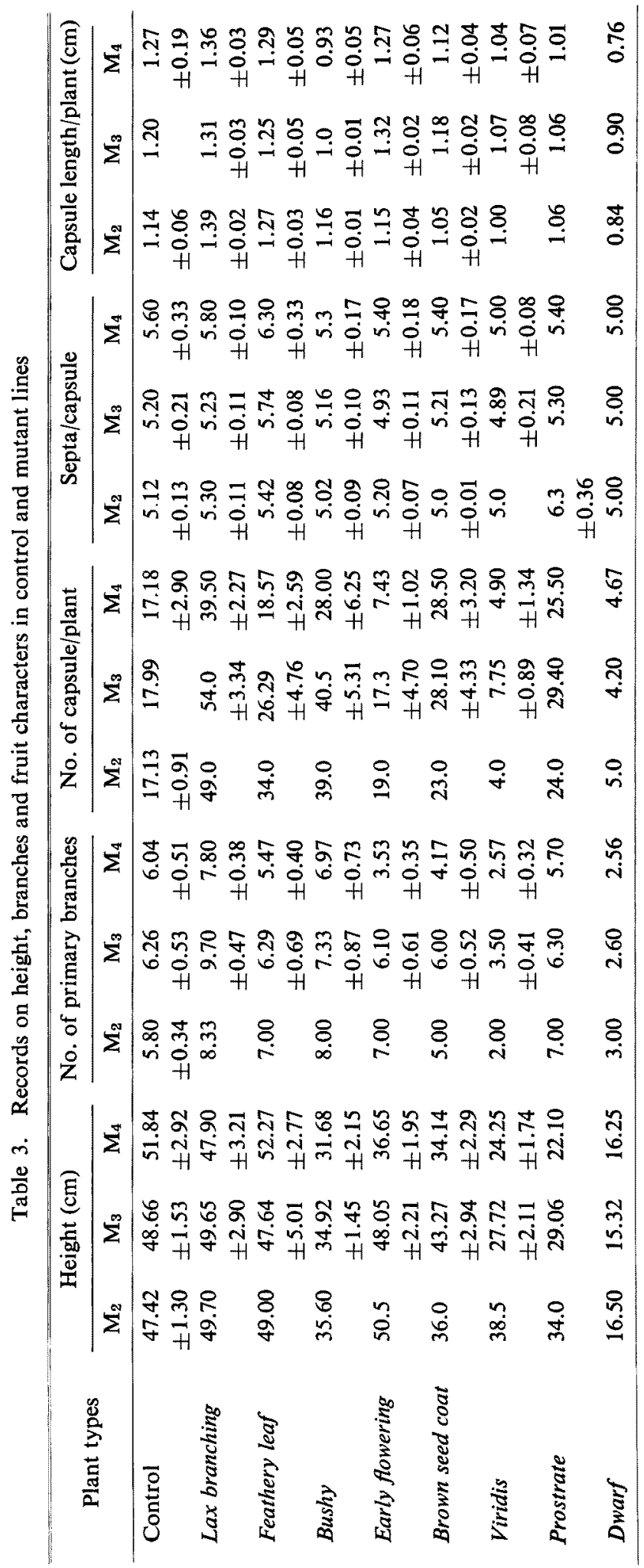




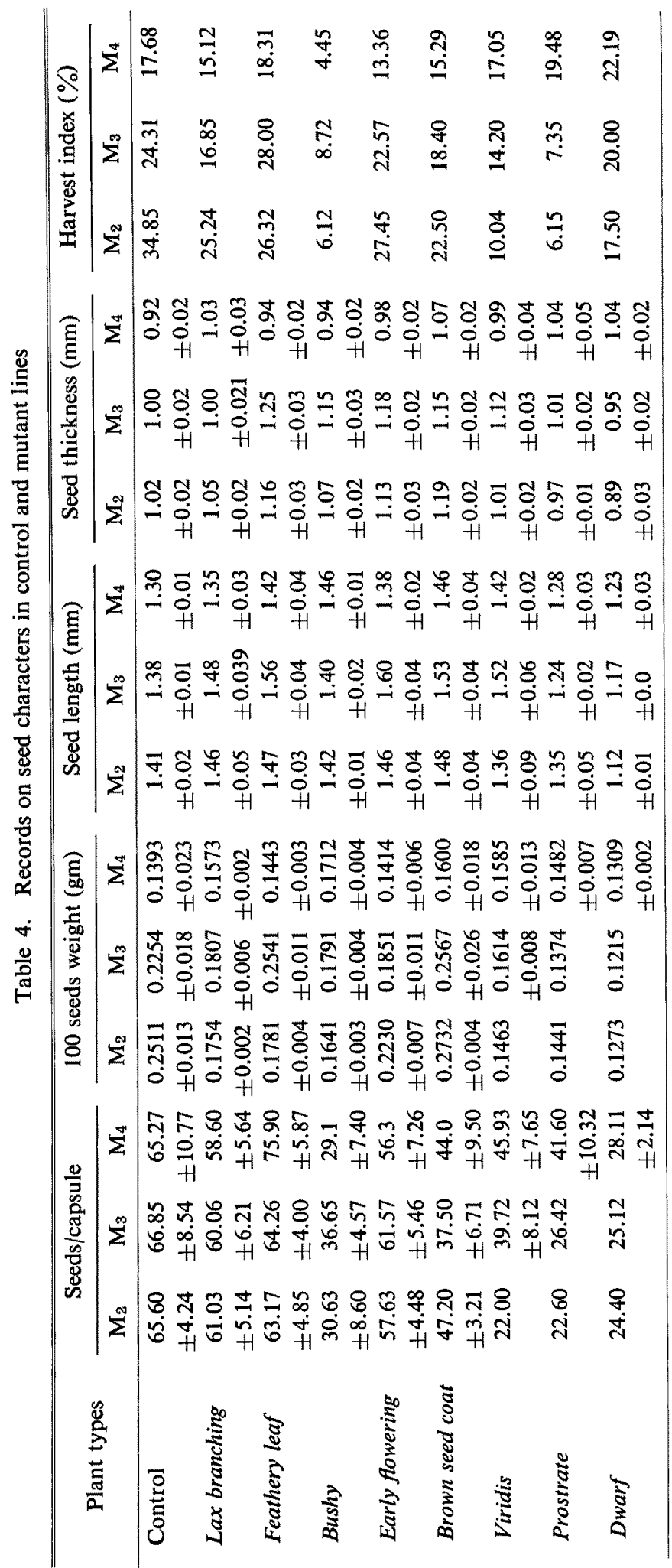



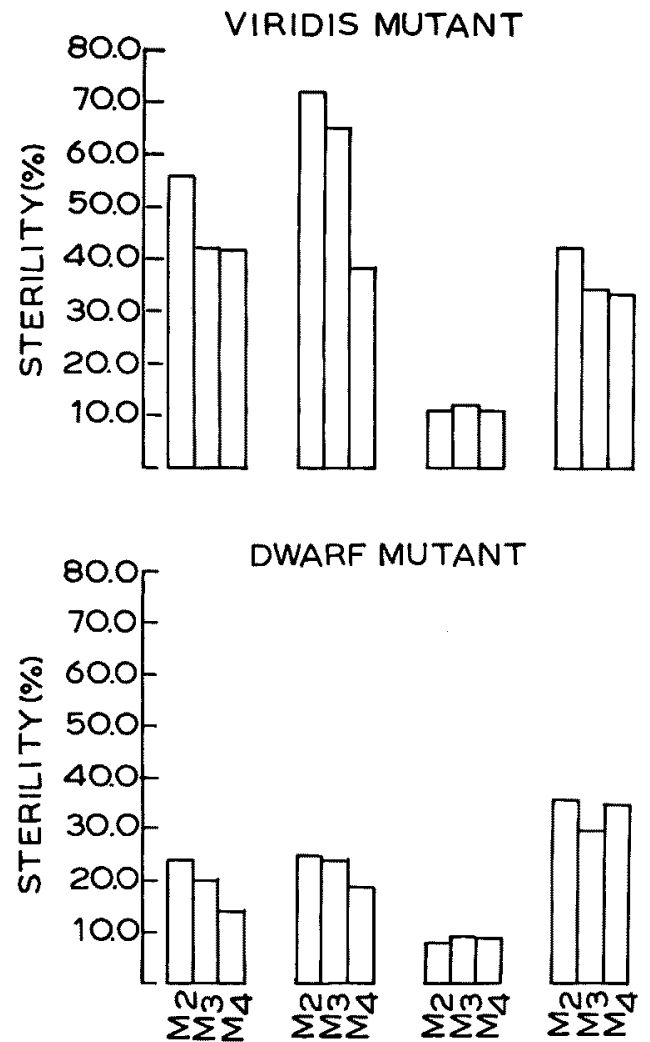

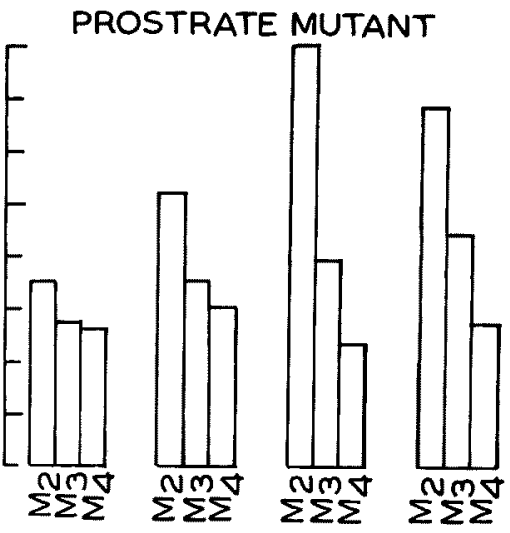

Fig. 2. Bar histograms represent different sterility types in control and in different mutants of $N$. sativa at $\mathbf{M}_{2}, \mathbf{M}_{3}$ and $\mathbf{M}_{4}$ generations.

Seedling mortality at younger stages was a common phenomenon in the mutant plants, but none of the seedlings of the bushy and prostrate mutants died even after 40 days of sowing as in case of control (Table 2, Fig. 1)

\section{Post-harvest findings and sterility types}

Tables 3 and 4 demonstrated a comparative account of different parameters recorded after harvest in control and eight mutant plants during $\mathbf{M}_{2}, \mathbf{M}_{3}$ and $\mathbf{M}_{4}$ generations. The number of primary branches was found to be increased in lax branching and bushy mutants, while total number of capsules per plant enhanced in lax branching, feathery leaf, bushy, brown seed-coat and prostrate mutant plants. Length and thickness of seed were found to increase in lax branching, feathery leaf, brown seed-coat and early flowering mutants, while septa per capsule and capsule length per fruit increased only in the feathery leaf and lax branching mutants. As compared to controls of the respective generations, reduced seed-setting was evidenced in the mutant plants, although the feathery leaf mutant of the $\mathbf{M}_{4}$ generation manifested increased seed setting. Considering the three generations studied, it is apparent that seed-setting is more or less normal in feathery leaf, lax branching and early flowering mutant lines. The brown seed-coat mutant was unique in producing heavier seeds than the control in all the generations; increased seed weight was, 


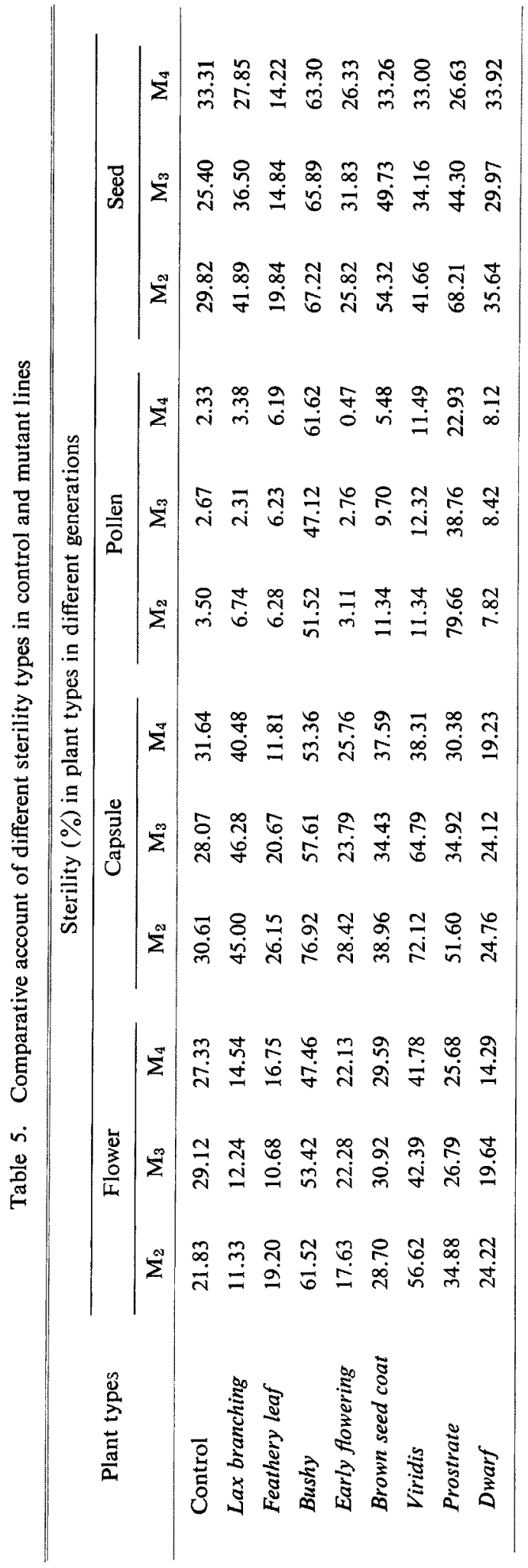




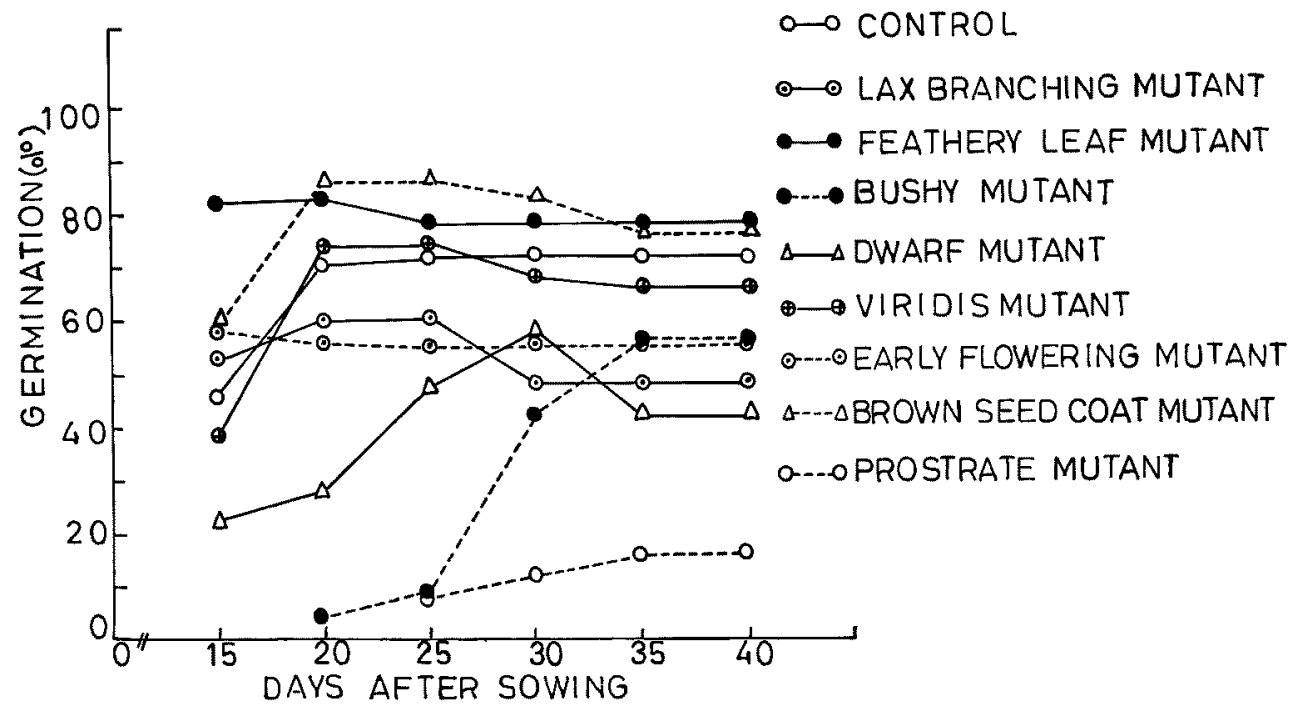

Fig. 3.

however, noted in the $\mathrm{M}_{4}$ generation of all but the dwarf mutant.

Thus, the survey of the mutant lines has disclosed that the mutants have exhibited superiority over the control plants in some of the characters only but not in all the parameters. This observation, therefore, opens up the possibility of direct selection of the desired mutant plant types as well as the scope of improvement through hybridization followed by proper selection, although the sterility barriers in the mutant plants needs to be minimized through repeated screening of the population. Compared to control, in the present investigation, all the sterility types (flower, capsule, pollen and seed) have been found to be conspicuously increased in the bushy, viridis and dwarf mutant plants; but all the sterility types, in general, have reduced gradually in the following generations (Table 5, Fig. 2).

\section{Variation in quantitative characteristic in control and mutant plants}

Significant year to year phenotypic changes have been recorded in the control plants of $N$. sativa regarding most of the traits excepting capsule length and filled seeds per capsule, when grown in the same season each year (Table 6). Certainly, environmental variations could be attributed for the differential responsiveness of the different parameters studied. Since the different characters of the control plants exhibited variations during different years, it would be logical to compare the mutant plant types (cited in Table 8) with control when grown in the same year under uniform agro-climatic conditions.

Comparison among the control and six different mutant plant types was restricted to ten different characters and mean values of the characters, $\mathrm{F} \%, \mathrm{CD}$ at $5 \%$, C.V. (coefficient of variation) and heritability (broad sense) were estimated. Significant variations have been noted in the different plant types for most of the traits excepting seed length and seed weight per plant (Table 7). In the control and mutant plant types, maximum and minimum variations as measured by co- 

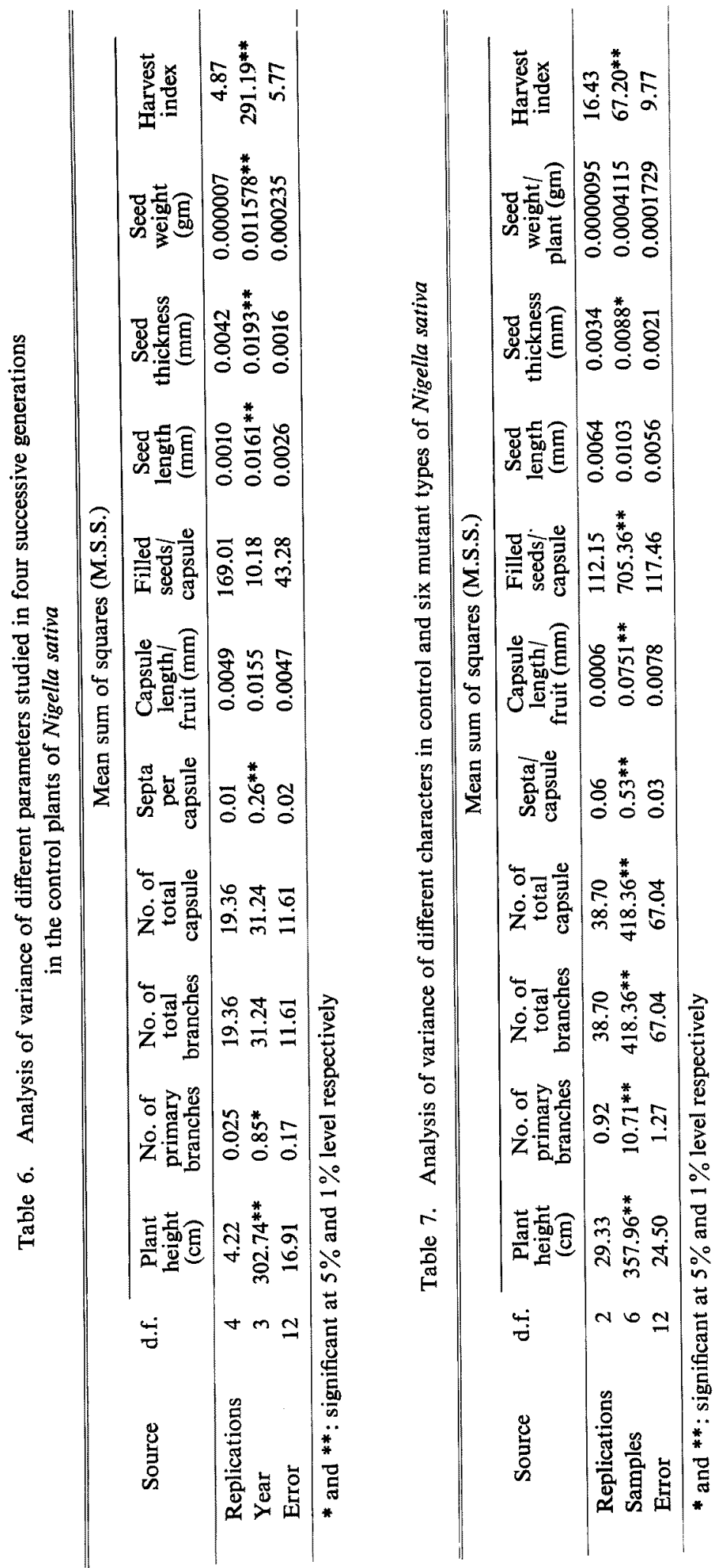


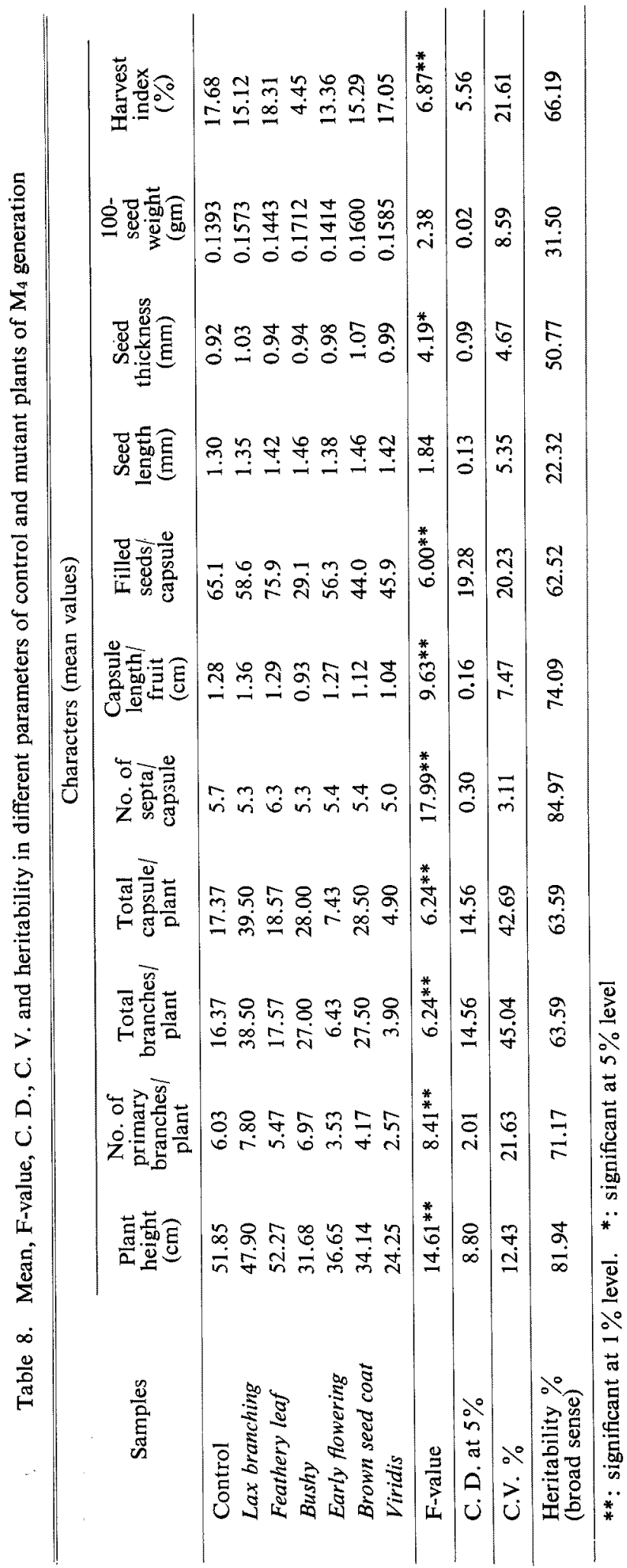


efficient of variations were recorded for total number of branches per plant and number of septa per capsule, while septa per capsule and seed length revealed highest and lowest value of heritability respectively (Table 8). In the $\mathrm{M}_{4}$ lines, different parameters of different mutants have exhibited superiority over control plants (Table 8).

Finally it may be concluded from the present investigation that there exist variations for most of the traits among the control and mutant plant types when grown in a uniform agro-climatic conditions; and furthermore different sterility types have reduced gradually in most of the mutant lines in the subsequent generations. Thus, the present study has not only facilitated the scope of selection of the mutant types but also brightened the possibility of proper utilization of the plant types for better yield through intercrossing.

\section{Summary}

Quantitative variations regarding germination, survival, plant height, number of primary and total branches per plant, capsule length and chamber per fruit, filled seeds per capsule, seed size (length and thickness), 100-seed weight, harvest index and sterility types (flower, capsule, pollen and seed) were assessed in control and eight mutant types-lax branching, feathery leaf, bushy, early flowering, prostrate, dwarf, brown seed-coat and viridis in $\mathbf{M}_{2}, \mathbf{M}_{3}$ and $\mathbf{M}_{4}$ generations. Year to year variations in yield attributing traits among control plants were studied. Analysis of variance performed in control and $\mathrm{M}_{4}$ mutant lines revealed significant variations in most of the phenotypic traits.

\section{Acknowledgement}

Financial assistance from University of Kalyani to the senior author is greatfully acknowledged.

\section{References}

Brock, R. D. 1977. Prospects and perspectives in mutation breeding. In Genetic Diversity in Plants. (Edited by Muhammed, A., Åksel, R. and Borstel, R. C. V.). 117-132 pp.

Datta, A. K. and Biswas, A. K. 1985 . Induced mutagenesis in Nigella sativa L. Cytologia 50: 545-562.

Gaul, H. 1964. Mutations in plant breeding. Rad. Bot. 4: 155-232.

Micke, A. 1969. Improvement of low yielding sweet clover mutants by heterosis breeding. In Induced Mutations in Plants. pp. 541-550. I.A.E.A., Vienna.

Sigurbjörnsson, B. 1976. The improvement of barley through mutation. In Barley Genetics III (edited by Gaul, H.). pp. 84-95. Verlag Karl Thiemig, Munich. 